\title{
Implicações do Diagnóstico na Aceitação da Criança com Deficiência: Um Estudo Qualitativo
}

\author{
Síglia Pimentel Hoher Camargo \\ Angélica Dotto Londero \\ Universidade Federal de Santa Maria
}

\begin{abstract}
RESUMO
Quando nasce uma criança com deficiência, o discurso do profissional da saúde no momento do diagnóstico assume um papel importante na forma como os pais irão lidar com essa nova e indesejada situação de vida. O presente trabalho teve por meta verificar as implicações do modo como é dado o diagnóstico médico e as orientações aos pais de crianças com deficiência, no seu processo de aceitação. Os dados foram coletados através de entrevistas individuais com oito pais de crianças com deficiência. As entrevistas foram transcritas e submetidas à análise de conteúdo. As cinco categorias identificadas demonstram que o diagnóstico é um momento importante para o processo de aceitação da criança com deficiência e para sua inclusão na família e na sociedade.
\end{abstract}

Palavras-chave: saúde; diagnóstico; criança com deficiência.

\section{ABSTRACT \\ Diagnosis and its Implications in the Acceptance Process of the Child with Disability: A Qualitative Study}

When a child is born with a disability, the speech of the health professional at the moment of diagnosis has an important role in the way that parents deal with this new and unexpected life situation. This paper aimed to verify the implications of the way that the diagnosis is given and provide guidance to parents of children with disabilities in their acceptance process. Data were collected through individual interviews with eight parents of children with disabilities and submitted to a content analysis. The five identified categories indicated that diagnosis was an important moment for the parent's acceptance process and for the child's inclusion in the family and society.

Keywords: health; diagnosis; children with disabilities.

Quando um a criança nasce, deposita-se nela uma série de expectativas que habitam o imaginário familiar e que foram idealizadas durante os nove meses de preparo e espera. Na verdade, os pais elaboram a ideia de ter um filho ainda na infância e, ao tornarem-se adultos, a criança desejada passa a existir mais intensamente no imaginário de cada um, possuindo características que correspondem aos seus próprios anseios e necessidades. Um filho representa a imortalidade dos pais, que o idealizam como um digno sucessor ou, se constitui num resgate de tudo o que não foi possível realizarem em suas vidas, sustentando a ilusão de que através dele isto será possível. Assim, um filho é, tanto para a mulher quanto para o homem, um investimento narcísico (Goes, 2006; Goldenstein, 1998; Maldonado, Dickestein \& Nahoun, 2002; Molina, 1998). Desse modo, o nascimento de um bebê com deficiência gera um sentimento aterrador de impotência e ambivalência em todos aqueles que estão envolvidos com o seu nascimento, especialmente os pais, para quem a criança incorporava diversas expectativas em relação ao futuro. Para esses pais, além de sobrepor-se uma carga de luto e adaptação, há a necessidade de aprender formas de cuidados especiais, tornando-se um desafio o exercício das mesmas. O bebê idealizado deixa de existir, uma vez que as divergências entre a criança ideal e a real são muitas vezes claras, constituindo-se numa total distorção do bebê sonhado ou planejado (Goes, 2006; Lago, 2001). O processo de luto torna-se necessário aos pais para poderem se vincular ao filho que vive. Isso pode, de forma gradual, levar meses, à medida que as solicitações da criança não perfeita ajuda a se desfazer dos sentimentos depositados numa criança perfeita e a 
perceber que, assim como outras crianças, seu filho chora, mama, sorri e precisa de atenção e afeto. Uma nova imagem da criança deve ocupar a mente dos pais, substituindo uma que não se concretizou. Para isso, é preciso que os pais tenham o tempo necessário para expressar seus sentimentos de raiva e culpa e realizarem efetivamente seu luto (Bazon, Campanelli \& Blascovi-Assis, 2004; Fiamenghi Jr. \& Messa, 2007, Nevez, 2003).

Os efeitos psicológicos imediatos da informação da deficiência de uma criança nos seus pais e o processo de aceitação variam com a história familiar, com a patologia do bebê e com a percepção dos pais em relação ao seu entorno. Podemos então citar o relacionamento de cada casal, a estrutura de personalidade de cada um dos pais, as experiências vividas em conjunto e individualmente como também a cultura na qual foram educados, no que diz respeito à convivência com as diferenças e o enfrentamento de eventos de vida frustrantes (Cohen e cols., 1994; Fiamenghi Jr. \& Messa, 2007). Além disso, a natureza da malformação pode determinar a reação dos pais e o grau de dificuldade na vinculação com o filho. Segundo Klaus, Kennell e Klaus (2000) "quanto mais visíveis os defeitos, mais imediata a preocupação e o constrangimento" (p. 152), uma vez que foge mais intensamente do socialmente instituído e desejado, da aparência como indicador de saúde. No entanto, além desses fatores cuja influência é significativa, outro aspecto importante afetará a vivência dos pais. Trata-se do momento em que souberam da notícia e ouviram ou reconheceram o estado da criança, bem como quem informou o problema e como este foi explicado (Ferrareto e cols., 1994; Hoher \& Wagner, 2006; Mendes, Nunes \& Ferreira, 2002).

Como observam alguns autores (Buscáglia, 1997; Klaus e cols., 2000; Mendes e cols., 2002; Moreno, 1996; Telford \& Sawrey, 1988), é muito comum os pais de crianças com deficiência demonstrarem insatisfação em suas experiências com profissionais que lhes informam ou orientam quanto aos problemas que o filho apresenta. Estudos empíricos realizados no Brasil, focando a satisfação dos pais em relação a forma como receberam a notícia da deficiência do filho são praticamente inexistentes. Ao contrário, a literatura internacional (Buscáglia, 1997; Quine \& Rutter, 1994), apresenta algumas pesquisas indicando a insatisfação dos pais com as informações recebidas a respeito do diagnóstico de seus filhos. Em geral, os profissionais diretamente envolvidos com os cuidados e a problemática da criança são rotulados pelos pais como pessoas insensíveis e sem compaixão, pela ma- neira objetiva e demasiadamente formal como thes passam notícias sobre o diagnóstico, bem como em relação às orientações e condutas necessárias para com a criança. Conforme apontam Klaus e cols. (2000), os pais encontram uma discrepância entre suas reações emocionais intensas e a formalidade por parte dos profissionais, muitas vezes determinada pela falta de preparo para comunicar o diagnóstico (Hoher \& Wagner, 2006). De acordo com Graungaard e Skov (2007), informar o diagnóstico de uma criança com deficiência aos pais é uma tarefa muito difícil para os profissionais. O momento da notícia e o período inicial subsequente caracterizam-se numa fase em que os pais estão extremamente sensíveis para captar a disponibilidade emocional do profissional para atendê-los e ouvi-los. Desse modo, como indica Buscáglia (1997) grande parte da reação inicial a essa notícia será determinada pelo tipo de informação fornecida, a forma como ela é apresentada e a atitude da pessoa que faz a comunicação. De fato, o estudo realizado por Graungaard e Skov (2007) com 16 pais de recém-nascidos com deficiência demonstrou que as reações parentais são altamente influenciadas pela informação do diagnóstico. A esse respeito, muitos profissionais são capazes de encontrar um equilíbrio entre as próprias dificuldades e preencher algumas necessidades de apoio dos pais. Porém, a realidade observada em diversas instituições de saúde (pública ou privada) aponta para a existência de uma extensa gama de profissionais que ainda não se encontram preparados para lidar com a comunicação do diagnóstico e o aspecto emocional que envolve o processo de luto dos pais frente a uma criança com problemas.

Do mesmo modo que a comunicação do diagnóstico pode se apresentar de uma forma traumatizante para os pais, o comportamento (positivo ou negativo) de alguns profissionais em relação à criança torna-se marcante. Em relação a isso Klaus e cols. (2000) afirmam: "em nossa experiência, os pais dão muita importância à abordagem e à atitude da equipe médica e de enfermagem. Embora com frequência não se lembrem das palavras exatas da enfermeira, do obstetra ou do pediatra, eles se lembram de sua atitude em geral" (p. 153). Um estudo realizado por Amorim, Moreira e Carraro (1999) demonstra que o impacto das atitudes profissionais frente a um diagnóstico de incapacidades no bebê, podem se constituir, inclusive, em fatores inibidores do processo de lactação, um momento importante para a vinculação entre mãe e filho. Os resultados indicaram que a forma como foi transmitida a notícia do nascimento de um filho com síndrome de 
Down, para a mãe, e o impacto desse fato em seu estado emocional, foi importantíssimo para a concretização ou não da amamentação.

Diante disso, é possível perceber que a atenção e o cuidado dos profissionais para com os pais e a criança é de extrema importância para a imagem e o conceito que eles formarão do filho. Ao lidarem com a criança de maneira respeitosa e cuidadosa, os profissionais transmitem aos pais a percepção de que eles a consideram humana, um indivíduo como todos os demais, digno de preocupação e aceitação. Da mesma forma, quando os pais são informados sobre o problema da criança a partir do que ela não poderá ser ou fazer, a mesma passa a ser vista sob a ótica de suas incapacidades, onde as limitações constituirão um fator preponderante em sua vida. Assim, essa ênfase comum dos diagnósticos médicos muitas vezes faz com que os pais voltem para casa com uma visão limitada, negativa e pessimista do filho. Muitas vezes, o encontro diagnóstico inicial é a única oportunidade de aconselhamento que alguns pais possuem, seja por falta de recursos ou de uma preocupação genuína para comparecer a futuras consultas, encontrando-se, desse modo, sozinhos e com o rótulo de um filho deficiente e incapaz. Buscáglia (1997) classifica os primeiros anos, do nascimento à infância da criança com deficiência, como cruciais, quando tanto os pais quanto à criança precisam de mais ajuda. É neste período que os pais serão a chave para ajudar os filhos a desenvolver atitudes básicas em relação à sua ótica futura. Portanto, torna-se imprescindível que os pais sejam informados, esclarecidos e orientados a respeito dos problemas do filho, da importância dos primeiros meses de vida e dos problemas que podem surgir. Isso quer dizer que devem ser acompanhados pelos profissionais da saúde em encontros subsequentes e orientados quanto às condutas que poderão facilitar um desenvolvimento adequado para a criança, de acordo com sua limitação. Para os pais, pode ser muito difícil compreender a grande importância que a criança tem de explorar o mundo ao seu redor. Em função disso, muitas crianças adquirem outras deficiências que poderiam ser evitadas. Além disso, conforme Brunhara e Petean (1999) e Parazzi e Dupas (2005), os profissionais devem conhecer as condições emocionais para lidar efetivamente com a realidade de cada família.

Em relação à doença orgânica crônica, Castro e Piccinini (2002), apontam que os pais buscam uma explicação clara sobre a doença do filho e suas consequências e sentem-se frustrados quando isso não acontece, podendo alimentar fantasias de culpa. A falta de oportunidade para conversar sobre o diagnóstico pode sobrecarregar os pais, fazendo sentirem-se incapazes de avaliar a realidade da anormalidade do filho. Desse modo, o processo de luto torna-se fixado como uma atmosfera mantida dentro da família e o fantasma da criança desejada e esperada, por vezes, continua a interferir na adaptação da família à criança real.

Exercer a função de pais de uma criança com deficiência é um papel novo e complexo. Para enfrentar esse desafio eles precisam dispor de um diagnóstico médico compreensível, conforto para sentimentos de culpa, incerteza e medo, bem como uma vaga ideia de como será o futuro para eles e para o filho. Os pais precisam ser encorajados para enfrentar estas dificuldades. Certamente, muitas serão as vezes em que os profissionais não terão todas as respostas e não estarão completamente seguros do prognóstico da criança, mas isto não impede que os pais possam ser informados sobre o que já pode ser cientificamente afirmado. Além disso, se forem informados e esclarecidos, a maioria dos pais compreenderá que no momento, um prognóstico específico se torna impossível e grande parte de suas ansiedades será reduzida. É necessário, portanto, que a ajuda seja canalizada aos pais, cuja influência suprema atravessa os primeiros anos de vida (Ferrareto e cols., 1994). Esta ajuda inicial aos pais, além da rede de apoio familiar deve ser prestada pelos profissionais de saúde, desde a forma como lhes anunciar a chegada de um bebê não esperado, até a explicação e orientação, conversando clara e abertamente sobre suas dúvidas e dificuldades. Segundo Silva (1988) e Rossel (2004), quanto mais adequada for a revelação do diagnóstico, menor será a situação de desamparo enfrentado pelos pais. Uma informação adequada do diagnóstico deverá considerar diversos aspectos como o fornecimento e esclarecimento do maior número de informações possíveis, atualizando e esclarecendo os pais quanto ao possível prognóstico a cada nova consulta. Uma conversa franca e aberta ao nível do entendimento dos pais enquanto prováveis leigos em relação ao problema do filho, o encaminhamento para outros profissionais de saúde e a empatia do profissional são importantes para o engajamento dos pais no processo que envolve o tratamento da criança. Além disso, o foco dos profissionais nas potencialidades da criança ao invés das dificuldades mostra-se fundamental para a percepção que os pais terão do filho.

Enfatiza-se nesse sentido, a importância da interpretação que a mãe faz em relação à criança e seu problema, o que pode reduzir ou aumentar as dificul- 
dades e criar eventualmente novos problemas para si e para a criança. Em relação a isso Buscáglia (1997) afirma que pesquisas clínicas têm revelado que a maior influência sobre a aceitação ou rejeição da criança deficiente pela família é a atitude da mãe. Se ela é capaz de lidar com o fato com aceitação e segurança razoáveis, de uma forma bem ajustada, a família será capaz de fazer o mesmo.

No entanto, para a mãe experimentar a vinculação com seu filho precisará chegar a uma aceitação no mínimo parcial ou uma adaptação a essa realidade. A partir daí ela permitirá que, acima de tudo, a criança seja incluída na família. Para isso será necessário que esse processo seja facilitado desde o princípio, pela família e pelos profissionais envolvidos com o diagnóstico e orientações. Esses devem ser realizados de forma que permitam os pais sentirem-se encorajados e partes importantes de um processo, cujo objetivo é ajudar na recuperação ou minimização das sequelas do filho. Assim, o modo como a criança deficiente será aceita na família e o resultante clima emocional dependerá em grande parte das explicações iniciais.

Considerando a importância do momento diagnóstico inicial para a aceitação de uma criança com deficiência, apontada pela literatura, o presente trabalho teve como objetivo verificar as implicações da forma como são fornecidos o diagnóstico médico e orientações pela equipe de saúde aos pais de crianças com deficiência, no seu processo de aceitação do filho. Buscando apreender e analisar a vivência dos pais de crianças com deficiências sobre o tema, optou-se por uma abordagem qualitativa dos dados.

\section{MÉTODO}

\section{Participantes}

Participaram deste estudo quatro pais de crianças com deficiência abaixo de seis anos e quatro pais de crianças com deficiência acima de seis anos. Buscando contrabalançar os dados com as vivências dos pais quanto ao diagnóstico em diferentes épocas, a idade de seis anos foi estabelecida como critério. Desse modo, foi possível obter relatos de pais que tiveram a experiência de receber o diagnóstico de um filho com deficiência há mais de seis anos ou mais recentemente. Cabe ressaltar que os participantes são denominados pais de crianças com deficiência. No entanto, tal denominação tanto inclui a coleta de dados com ambos (pai e mãe), quanto apenas com um membro da díade parental (pai ou mãe). Desse modo, dos oito casos participantes houve um em que o casal (pai e mãe) participou e cuja entrevista foi realizada em conjunto. Nos demais casos a participação foi somente da mãe. Características adicionais dos participantes encontram-se nas Tabelas 1 e 2.

TABELA 1

Caracterização dos Pais de Crianças Abaixo de Seis Anos

\begin{tabular}{|c|c|c|c|c|c|}
\hline PAIS & Mãe 1 & Pai 1 & Mãe 2 & Mãe 3 & Mãe 4 \\
\hline Idade & 33 & 34 & 26 & 34 & 25 \\
\hline Escolaridade & $1^{\circ} \mathrm{Grau} \mathrm{C}$ & $1^{0} \mathrm{Grau} I$ & $2^{\circ} \mathrm{Grau} \mathrm{C}$ & $1^{\circ} \mathrm{Grau} I$ & $1^{\circ} \mathrm{Grau} \mathrm{C}$ \\
\hline Profissão & Dona de casa & Balconista & Dona de casa & Dona de casa & Dona de casa \\
\hline $\begin{array}{l}\text { Idade no nascimento } \\
\text { do filho }\end{array}$ & 33 & 34 & 24 & 30 & 19 \\
\hline $\begin{array}{c}\text { Forma como recebeu } \\
\text { o diagnóstico }\end{array}$ & \multicolumn{2}{|c|}{ Péssima } & Ruim & Boa & Boa \\
\hline CRIANÇA & \multicolumn{2}{|c|}{ Criança 1} & Criança 2 & Criança 3 & Criança 4 \\
\hline Sexo & \multicolumn{2}{|c|}{$\mathrm{F}$} & $\mathrm{F}$ & $\mathrm{F}$ & $M$ \\
\hline Idade & \multicolumn{2}{|c|}{15 dias } & 1 ano & 3 anos & 5 anos \\
\hline Diagnóstico & \multicolumn{2}{|c|}{$\begin{array}{l}\text { Meningo- } \\
\text { Mielocele }\end{array}$} & Hemiparesia & $\begin{array}{c}\text { Atraso NPM, } \\
\text { Sopro Cardíaco }\end{array}$ & $\begin{array}{l}\text { Paralisia } \\
\text { Cerebral }\end{array}$ \\
\hline $\mathrm{N}^{0}$ irmãos & \multicolumn{2}{|c|}{3} & 1 & 1 & \\
\hline (Sexo-Idade) & \multicolumn{2}{|c|}{$\left(F-12 ; F-3 ; F-1^{a} 3 m\right)$} & (M-8) & $(\mathrm{F}-13)$ & - \\
\hline Posição na família & \multicolumn{2}{|c|}{$4^{a}$ filha } & $2^{a}$ filha & $2^{a}$ filha & Filho único \\
\hline Concepção desejada & \multicolumn{2}{|c|}{ Não } & Sim & Não & Sim \\
\hline
\end{tabular}


TABELA 2

Caracterização dos Pais de Crianças Acima de Seis Anos

\begin{tabular}{|c|c|c|c|c|}
\hline PAIS & Mãe 5 & Mãe 6 & Mãe 7 & Mãe 8 \\
\hline Idade & 40 & 36 & 58 & 32 \\
\hline Escolaridade & $1^{\circ} \mathrm{Grau} I$ & $2^{\circ} \mathrm{Grau} \mathrm{C}$ & $1^{\circ} \mathrm{Grau} I$ & $2^{\circ} \mathrm{Grau} \mathrm{C}$ \\
\hline Profissão & Faxineira & Dona de casa & Dona de casa & Dona de casa \\
\hline $\begin{array}{l}\text { Idade no nascimento } \\
\text { do filho }\end{array}$ & 27 & 26 & 51 & 19 \\
\hline $\begin{array}{c}\text { Forma como recebeu } \\
\text { o diagnóstico }\end{array}$ & Boa & Péssima & Péssima & Ruim \\
\hline CRIANÇA & Criança 5 & Criança 6 & Criança 7 & Criança 8 \\
\hline Sexo & $M$ & $\mathrm{~F}$ & $M$ & $M$ \\
\hline Idade & 13 anos & 9 anos & 7 anos & 12 anos \\
\hline Diagnóstico & $\begin{array}{c}\text { DM moderada } \\
\text { AGD }\end{array}$ & Paralisia Cerebral & Sindrome de Down & $\begin{array}{c}\text { Má formação corpo } \\
\text { caloso }\end{array}$ \\
\hline $\mathrm{N}^{0}$ Irmãos & & 3 & 3 & 2 \\
\hline (Sexo-Idade) & - & (F-5; M-17; M-9) & (M-19; F-17; F- 9) & $(\mathrm{M}-21 ; \mathrm{F}-6)$ \\
\hline Posição na família & Filho único & $2^{a}$ filha & $4^{a}$ filho & $1^{a}$ filho \\
\hline Concepção desejada & Sim & Sim & Não & Sim \\
\hline
\end{tabular}

\section{PROCEDIMENTOS E CONSIDERAÇÕES ÉTICAS}

Para realizar este estudo, contatou-se a direção de uma escola para crianças com deficiências do município de Santa Maria/RS. Foi apresentada a proposta de pesquisa e solicitada a permissão, através de uma carta de apresentação, para a realização das entrevistas com alguns pais dos alunos que vão à escola para os atendimentos clínicos oferecidos pela mesma. Conferido o consentimento da escola, escolhida por ser um meio de acesso rápido aos pais de crianças com deficiência, procurou-se contatar, com a ajuda da secretária, aqueles que se encontravam de acordo com o critério de idade previamente estabelecido. Assim, obteve-se uma amostra por critério de conveniência. Mediante a abordagem, apresentação pessoal e explanação da natureza e finalidade do estudo, foi marcado um dia e horário para efetivar a participação dos pais, de acordo com as possibilidades do interessado. Os pais de crianças com deficiência envolvidos no estudo receberam do pesquisador os esclarecimentos necessários sobre a pesquisa na forma de explicação oral pormenorizada e, por escrito, receberam o termo de consentimento livre e esclarecido. Este foi elaborado de acordo com as determinações do Conselho Federal de Psicologia e com base na resolução MS 196/96 que versa sobre as diretrizes e normas regulamentadoras de pesquisas envolvendo seres humanos, garantindo o sigilo das informações coletadas. O consentimento do participante por escrito tornou-se imprescindível, constituindo-se, portanto, num dos critérios de participação do estudo.
Apenas um dos pais foi contatado através da maternidade do Hospital Universitário da Universidade Federal de Santa Maria, onde foi realizada a coleta dos dados, os demais participantes foram contatados através da escola.

\section{Instrumentos e materiais}

Para a realização desta pesquisa, foi elaborado um roteiro de entrevista semiestruturada, com algumas questões norteadoras que dão conta de extrair os relatos de interesse da pesquisa. A técnica de entrevista, como instrumento de coleta de dados, mostra-se adequado, pois através dela o sujeito expressa através da fala e da verbalização seus valores, crenças, representações, concepções e sentimentos em relação à temática abordada. As questões elaboradas não se fecham em si mesmas, mas permitem ao entrevistado ficar livre para descrever sua vivência e ao entrevistador, esclarecer as lacunas provenientes do campo de entrevista, configurado pelas variáveis que dependem da personalidade do entrevistado.

O roteiro de entrevista semiestruturada para os pais de crianças com deficiência consiste de 16 questões norteadoras e mais uma específica, para ser realizada de acordo com a resposta do participante. O primeiro item refere-se a dados pessoais da criança, da mãe e do pai. Por tratar-se de uma temática que pode proporcionar algumas defesas e ansiedades nos pais, o roteiro foi elaborado e ordenado, de modo que inicia com questões menos ansiogênicas, sucedidas por ou- 
tras que levam até o foco principal do que se deseja investigar e que pode, de algum modo, causar maior ansiedade. Desse modo, as primeiras questões dizem respeito ao relacionamento do casal e suas expectativas em relação a ter filhos. Posteriormente, as questões foram sendo direcionadas para a vivência dos pais e suas reações ao receberem a notícia de que o filho possuía deficiência, bem como para um relato e avaliação da forma como eles receberam esta informação.

As entrevistas realizadas com os pais foram realizadas em um único encontro que durou, em média 40 minutos. Todas as entrevistas foram gravadas e transcritas mediante a autorização e consentimento dos participantes.

\section{ANÁLISE DOS DADOS}

A partir dos relatos coletados, empregou-se a análise qualitativa dos dados através da técnica de análise de conteúdo proposta por Bardin (1977). Para isso, foram percorridas as etapas de pré-análise, exploração do material, tratamento dos resultados, inferência e interpretação. Visando descrever os 'núcleos de sentido' presentes no conteúdo dos relatos dos participantes, tomou-se como unidade de análise os temas, ou seja, as orações ou enunciados com relação ao discurso a cerca do assunto investigado "e cuja presença, ou frequência de aparecimento, podem significar alguma coisa para o objetivo analítico escolhido" (Bardin, 1977, p. 105). Assim, as falas foram elencadas e agrupadas em categorias de análise, para, a partir de então, ser possível visualizar claramente as questões mais relevantes trazidas em relação ao tema. Desse modo, a categorização dos dados foi realizada a posteriori, ou seja, com base nas entrevistas realizadas. Para tanto, foram observados os critérios de recorrência do conteúdo, a intenção da mensagem, a pertinência, e a homogeneidade.

\section{RESULTADOS E DISCUSSÃO}

Visando manter o sigilo necessário em relação aos participantes, eles serão identificados de acordo com aquele que forneceu as informações (a mãe ou o pai mesmo no caso em que os dois participaram juntos), seguido de um número, o diagnóstico e a idade do filho (Ex: Mãe 1 - meningomielocele, 15 dias; Mãe 7, síndrome de Down, sete anos). Assim, a partir dos relatos dos participantes e partindo da unidade de análise por temas, foram extraídas as seguintes categorias a serem discutidas a seguir: A vivência dos pais
- Negação e Revolta: expressão de uma frustração; A informação e suas implicações - A falta de esclarecimentos: consequências para o desenvolvimento da criança; A maneira de informar: abrindo ou fechando possibilidades; A forma de comunicar o diagnóstico: implicações; A palavra dos pais.

\section{A vivência dos pais - negação e revolta: expressão de uma frustração}

Frente a todas as expectativas que são normalmente criadas em relação à criança, inevitavelmente os pais serão frustrados em alguns aspectos. Entretanto, quando ocorre confirmação posterior de que a criança possui alguma deficiência, tal situação origina grande inquietação e angústia nos pais e na família (Brito \& Dessen, 1999; Goes, 2006; Viana, Giacomoni $\&$ Rashid, 1994). Desse modo, para os entrevistados, saber que seu filho teria alguma necessidade especial representou a desconstrução da imagem de um filho idealizado. $\mathrm{O}$ choque frente à notícia ou a percepção de que a criança possuía algum problema geraram reações de surpresa, dúvida, negação e revolta. Pode-se perceber também, na fala dos entrevistados, que num processo constante de negação, muitos acreditam que seus filhos podem melhorar ou desenvolver habilidades que não possuem:

... foi uma surpresa assim, porque como eu falei, a gente fez ultra-som, tava tudo bem, ai de repente acontece um problema assim, um problema grave e eu fico surpresa, mas eu não consigo até agora imaginar assim, que ela não vai andar sabe, eu olho pra ela e eu sinto assim, do fundo do meu coração que ela vai andar ... (MÃE 1 - meningomielocele - 15 dias).

Quando ela nasceu, eu fiquei sabendo que ela tinha várias doenças. Até, uma vez me chamaram correndo, porque ela tava morrendo. E aí, fiquei muito... bom, me desesperei, né [...] a doutora disse que ela ia morrer, que daquela noite ela não passava. Bom, dai eu me desesperei, quebrei tudo dentro de casa, e fui correndo pro hospital ... (MÃE 3, atraso neuropsicomotor, sopro cardíaco, três anos).

Conforme Canho, Neme e Yamada (2006), os pais, assim como as mães, vivenciam ansiedade, angústia e descompensação emocional ao receberem o diagnóstico da deficiência do filho. Muitas vezes, a frustração por ter gerado um filho imperfeito, aliada à falta de informação, é amenizada quando se projeta no outro a culpa pelo que aconteceu. Assim, o sofrimento da mãe que, com o ônus de ter gestado um filho com proble- 
mas naturalmente se culpa, torna-se mais intenso quando a família ou o companheiro a culpam:

Eu fiquei muito triste porque o esposo me culpou por causa, assim, no caso, que eu não tomei cuidado direitinho, que eu não tomei a medicação direitinho, que foi por isso né que..., e eu fiquei triste. (MÃE 7, síndrome de Down, sete anos).

Para algumas a demonstração de força e de não se deixar abalar torna-se uma formação reativa e se faz necessária para o equilíbrio emocional, mas, por vezes, a frustração surge escondida:

Sabe, a gente fica triste, assim... dá uma coisa, mas não, não pode se entregar. [...] A gente não queria, mas também não fico, chorando, chorando por causa do problema. Sabe que eu nunca, acho que chorar, quando eu choro, eu só choro sozinha. (MÃE 8 , má-formação congênita do corpo caloso, 12 anos).

A presença de uma criança com deficiência exige que o sistema familiar se organize para atender às suas necessidades especiais. Esse processo pode durar dias, meses ou anos e mudar o estilo de vida da família, seus valores e papéis (Fiamenghi Jr. \& Messa, 2007; Silva \& Dessem, 2001). Neste sentido, a mudança no estilo de vida e nos planos de toda a família pela chegada do bebê especial aparece como um fato marcante e dolorido:

A gente foi perceber quando ele ia fazer três anos [...] eu levei, fiz exame, fiz elétro e não deu nada. $O$ médico disse que ele ia ter uma sequela, só que ele não me disse o que o guri tinha. Ai tá, fui embora, depois levei de volta pro pediatra e o pediatra disse: não o teu filho tem um plobleminha [...] ai que eu fui descobri que ele estava com poblema, tinha deficiência mental e daí a minha vida já mudou, não era aquela vida que eu tinha planejado sabe [...] ai eu larguei todo o serviço que tinha pra atender ele, dai até não pretendemos ter mais filhos por causa disso aí. (MÃE 5 - deficiência mental, 13 anos).

Do mesmo modo, é difícil pensar no futuro do filho e perceber ou imaginar que ele pode ser diferente de todos e, principalmente, do que foi esperado:

O esposo se preocupou muito, agora ele deixou um pouco, mas quanto ao futuro dele, né: não vai casar, não vai ter família, futuro nenhum, não tem aquela expectativa. Agora até que ele se aquietou mais. De tanto conversar com ele, mas ele sabe que eles têm muita, eles progridem, que eles têm, né, um potencial, os educadores falam com a gente, né. (MÃE 7, sindrome de Down, sete anos).
Dentre as diversas reações, a negação surge na tentativa de encontrar uma resposta contrária, que ainda lhes permita encontrar o filho idealizado. Desse modo, conforme Ferrareto e cols. (1994) os pais não hesitam em procurar a opinião de outro profissional que cumpra esse papel:

Foi na hora, não tinha terminado a cesárea ainda dai a pediatra foi lá e eu vi que quando ela nasceu foi aquele tumulto lá olhar [...] daí vem a pediatra assim em cima de mim com umas luvas e disse assim "Mãe ela nasceu com uma má formação e ela não vai andar". Ai eu imaginei a guria toda deformada assim né, me deu aquele [...] ai eu olhei assim, com uma cara acho que tão de desespero pro médico que tava fazendo a cesárea e ele olhou pra mim assim e fez um olhar como quem diz, não é tanto né e a gente se entendeu assim só nos olhares, ai eu fiquei esperando né [...] então foi esse médico que disse, dai ele disse com essas palavras, o que tava fazendo a cesárea né "Não, ela nasceu com uma má formação na coluna, é uma falta de tecido, mas parece que ela está mexendo as pernas", então foi ele assim que me acalmou ... (MÃE 1 - meningomielocele - 15 dias).

No entanto, mais do que a palavra do médico, é preciso ver para acreditar. Visualizar o bebê é não somente uma tentativa de encontrar indícios para reforçar a negação como a oportunidade de os pais confrontarem sua fantasia em relação aos problemas do filho com a realidade. Neste sentido, pode-se perceber que quanto mais aparente fisicamente a deficiência da criança, mais intensa será a reação de negação ou revolta:

E eu só olhei pra ela e disse assim "Não vai andar" e ela disse: "Não" e eu disse assim "ta, eu só quero ver ela", dai ela saiu assim e disse "eu vou terminar de arrumar ela, se der a gente te mostra", eu disse não, eu quero ver agora, e ela "tá, então tu aguarda um pouquinho "[...] quando ela trouxe ela toda enroladinha assim, dai mostrou o rostinho dela só, né, ai eu disse "eu quero ver a coluna" [...] ai como ele me falou que era na coluna quando ela me mostrou o rostinho assim no bercinho, eu pedi pra ver a coluna, dai ela destapou e eu pedi pra descobrir mais pra eu enxergar as perninhas dela ai eu vi que ela era perfeitinha e tudo, só tinha aquela falta de tecido ali e ela sentia a perna por que ela ainda movimentava um pouco né, dai que eu me tranquilizei... (MÃE 1 - meningomielocele - 15 dias).

A busca por explicações causais também aparece como uma necessidade dos pais na tentativa de entender o porquê, aliviando muitas vezes, culpas inconscientes. Além disso, a necessidade de compreender o 
problema do filho é uma necessidade de conhecê-lo, o que é imprescindível para a realização dos cuidados básicos do mesmo. Desse modo, os profissionais necessariamente devem oferecer aos pais todas as informações necessárias pra auxiliá-los nesse processo, evitando deixá-los perdidos frente a um filho e uma situação desconhecida:

Eu fiquei pensando assim, mas o que será que aconteceu [...] se é referente à medula pode ser um problema genético, eu fiquei pensando assim, entre o espaço que ela falou, depois que o médico falou, dai eu me orientei um pouco assim, mas é um susto... (MÃE 1 - meningomielocele - 15 dias).

... eu pensava assim oh, aparentemente uma criança com sindrome, com alguma coisa assim ela não é, mas tinha alguma coisa de estranho nela, tinha alguma coisa de diferente das outras crianças. Mas tu é leiga, tu não sabe definir o que é ou identificar assim o que é aquilo ali, mas tu sente que é diferente. (MÃE 2 - hemiparesia, um ano e seis meses).

A dificuldade em aceitar o diagnóstico leva a uma constante busca de cura (Bunhara \& Petean, 1999). Assim, no percurso de uma reação inicial de negação, dúvida e busca por resposta contrária àquela que foi ouvida ou ao que se imagina, a palavra do profissional da saúde assume uma dimensão fundamental:

Eu ficava olhando as outras crianças né e eu dizia assim, bah a L. não faz nada disso, e eu me lembro que eu falava pro meu marido e ele dizia assim: "Ah, mas tu tem que ver que o médico já te falou que ela é prematura ..." (MÃE 2 - hemiparesia, um ano e seis meses).

\section{A informação e suas implicações: a falta de esclarecimentos: consequências para 0 desenvolvimento da criança}

Logo que os pais percebem que algo está errado com a criança ou que lhes fornecem o diagnóstico do problema, pode-se perceber nos relatos a necessidade imediata de esclarecimentos. Seja pela busca de possibilidades contrárias ao fato de a criança ter nascido com uma deficiência, seja para sentirem-se valorizados ou compreenderem o que esperar das condições de saúde de seu filho. É muito angustiante para os pais não poderem nomear o problema do filho e não sentirem-se informados o suficiente para não criarem fantasias tanto em relação à criança quanto à sua (in)capacidade de fazer algo por ela (Fiamenghi Jr. \& Messa, 2007; Parazzi \& Dupas, 2005). Essa necessi- dade aparece com um tom de queixa pela falta de disponibilidade e atenção do profissional:

Teve uma coisa que eu queria ter feito, que a gente não conseguiu né, o médico que fez a cirurgia nunca falou com nós [...] e a gente achou falta que a gente tava lá embaixo esperando [...], ela já tava na sala de recuperação e a enfermeira disse que ainda tava em andamento, aí nunca conversou com nós [...] eu disse meu Deus, mas que tanta demora por que, poderia ter a possibilidade de já colocar uma válvula na cabecinha e a gente pensou, bom se tá demorando é por que precisou e ai mais desesperado a gente ficou né e se a gente soubesse 'oh, acabou, ela tá se recuperando', não, a gente ficou duas horas com o coração saindo pela boca lá, nem enfermeiro, nem médico, ninguém disse nada né ... (MÃE 1 - meningomielocele - 15 dias).

Associado à fragilidade emocional em que os pais se encontram, a falta de esclarecimentos pode voltar-se de forma agressiva ao profissional, levando à conflitos entre médico e paciente (Höher \& Wagner, 2006; Soar Filho, 1998) como demonstra esse relato:

... eu comecei a notar que ela era diferente das outras crianças desde o quarto mês de vida [...] eu falava pros médicos e eles diziam que era normal porque ela era prematura, que ela ia ser mais lenta, mais atrasada e foi passando, todos os meses eu falava sempre eu tinha a mesma resposta, ai com nove meses que ela foi passada pra uma neurologista [...] ela disse 'não precisa te preocupar que ela vai ser esquerda', ela vai ser canhota, ai eu disse pra ela bom, se for pra eu passar uma manhã inteira sentada aqui pra ouvir que ela vai ser canhota, então não precisa nem marcar retorno que eu não vou trazer mais ela, ai ela disse assim 'ah tu que sabe a tua filha precisa de um acompanhamento', dai eu disse assim: é, ela precisa de um acompanhamento, de um acompanhamento médico, não pra eu perder uma manhã inteira sentada pra ouvir que ela ia ser canhota, se fosse pra mim ouvi isso, isso eu já sabia por que ela só meche o lado esquerdo... (MÃE 2 hemiparesia, um ano e seis meses).

Além disso, quando os pais querem fazer algo para melhorar a condição de saúde do filho e não são esclarecidos e orientados, tomam iniciativas próprias, fazendo o que lhes parece pertinente, o que pode ser prejudicial à saúde da criança. Além disso, os pais muitas vezes centralizam atenções e cuidados para ela em detrimento dos demais filhos:

Aí eu comecei a cuidar, não é cuidar, cuidar eu já cuidava né, mas eu comecei a dar mais atenção pra ela, porque eu sabia que ela ia precisar mais de mim do que os outros que eu tinha. Ele (o marido) tam- 
bém ajudava a dar mais atenção pra ela e o resto normal, assim só com aquela coisa que tinha que não tava bem. (MÃE 6 - paralisia cerebral, nove anos).

Por isso, quando questionados sobre a forma que receberam o diagnóstico, os pais demonstram, tanto na situação em que se consideraram informados, quanto na que não se consideraram que, para sentirem-se esclarecidos e orientados, é preciso que os profissionais digam o que a criança tem e quais as suas possibilidades:

[...] ela foi dura e seca e eu acho que ela deveria explicar melhor [...] o que seria mesmo a doença porque ela só disse que a guria não ia caminhar e não disse porque. (MŨE 6 - paralisia cerebral, nove anos).

Sim, depois a pediatra nos chamou e falou tudo direitinho. (MÃE 7, sindrome de Down, sete anos).

A importância disso aparece no sentido da busca de recursos e tratamento adequado desde cedo, evitando que a impotência tome o lugar da ação legítima (Oliveira \& cols., 2004). Segundo Starke e Moller (2002) a satisfação ou insatisfação dos pais em relação à forma como receberam o diagnóstico tem influência na busca de informações e estratégias para lidar com as dificuldades do filho. A partir do momento em que forem esclarecidos, os pais podem buscar recursos que ajudem a minimizar as limitações da criança, favorecendo seu desenvolvimento:

Fomos, bem esclarecido, do problema e o que procurar. Nós não deixamos vegetando em casa, sabe, porque ele fez (o exame) com três meses e com 6 meses já tava aqui fazendo tratamento, né. Com dois meses, quer dizer, né, fez o exame e já procuramos recurso (MÃE 8, má-formação congênita do corpo caloso, 12 anos).

\section{A maneira de informar: abrindo ou fechando possibilidades}

O momento de receber a notícia e esclarecimentos sobre os problemas do filho, surge nos relato dos pais como um momento muito difícil não só pela natural frustração, quanto pela maneira com que os profissionais da saúde informam o diagnóstico. Desse modo, três dos pais entrevistados classificaram a forma como receberam a notícia como péssima:

Foi péssimo. Por que ela foi dura e seca, e isso angustia. (MÃE 6 -paralisia cerebral, nove anos).
É, eu achei péssima a maneira que ela falou, que ele não tinha solução, né, que pra ele não adiantava gastar nada, que não tinha dinheiro, nada, ia adiantar. Isso é que eu achei péssimo, né, a maneira que ela falou, né. (MÃE 7, sindrome de Down, sete anos).

É péssima, na hora ela (a pediatra) foi péssima [...] o médico que fez a cirurgia nunca falou com nós, sempre a gente passa pra eles e eles passam pra nós $n e ́$, a gente pede o horário e ele nunca tem [...] e nem na cirurgia, nem quando começou, nem quando terminou, ele não falou com nós né e a gente achou falta que a gente tava lá embaixo esperando né, na salinha ali... (MÃE 1 - meningomielocele - 15 dias).

Dois dos pais entrevistados julgam que a forma como foi dado o diagnóstico foi ruim, pois a maneira como os profissionais informaram se apresentou com um caráter definitivo e sem soluções, apresentando a realidade de um filho imperfeito e tirando todas as suas esperanças e motivações para investir econômica e emocionalmente em seu filho. Desse modo, aparece o sentimento de terem sido agredidos e a necessidade de saber a verdade, sem ilusões, porém de uma forma menos agressiva:

\begin{abstract}
Ah, foi ruim, ela não soube dizer, porque ela deu o diagnóstico e já quis fazer a previsão do futuro. Então foi muito mal colocado, ela não foi boa [...] Ela disse que o problema dele era sério e que a vida dele era assim, sabe, que ele não ia caminhar, não ia falar, não ia, assim... Ela não quis dizer que ia vegetar, mas que era bem grave [...] Isso ai que eu acho que ela fez péssimo. Não precisava iludir, mas também não precisava, né! É primeiro filho meu, e pegar e chegar... (MÃE 8, má-formação congênita do corpo caloso, 12 anos).
\end{abstract}

Eu acho que foi de uma forma ruim, pra não dizer péssima né [...] (MÃE 2 - hemiparesia, um ano e seis meses).

Conforme Höher e Wagner (2006) o sofrimento é sempre inevitavelmente grande na situação em que os pais são frustrados com a chegada do filho não esperado. No entanto, esse sofrimento pode ser intensificado quando são brutalmente frustrados pela forma com que é dada a notícia. Nota-se ainda, que orientações informais, fornecida por parentes e amigos e não pelo profissional, acabam dirigindo as ações da família e permitindo que ela veja seu filho como um ser humano que possui potencialidades:

Arrasada, né, porque, fiquei assim sem solução. Primeiro que eu não sabia que tinha solução, que 
tinha recursos pra ele, então eu fiquei lá embaixo [...] mas depois tu, no decorrer do tempo, assim, um fala uma coisa, ou te orienta assim, e tu vai vendo que não é bem assim, né. Que tudo pode [...] que eles podem ser alguém na vida... (MÃE 7, síndrome de Down, sete anos).

Saber exatamente o que seu filho tem e suas possibilidades é o que os pais querem e precisam para elaborar o luto do filho ideal perdido. Desse modo, quando a forma com a qual os profissionais informam é considerada boa ou satisfatória, é isso que acontece. Três dos pais entrevistados consideraram boa a forma como receberam a notícia:

Pelo que ele explicou foi bom, né, por um lado foi bom. Pelo lado que ele explicou pra nós, o que ele poderia ter, o que ele poderia não ter. (MÃE 4, paralisia cerebral, cinco anos).

É, foi boa. Porque sim, eu, deu pra entender, né... (MÃE 3, atraso neuropsicomotor, sopro cardíaco, três anos).

Ah, pra mim até foi bom porque foi uma coisa assim que aquilo tirou o meu sofrimento, eu pensava o que é que o meu filho tinha [...] ele foi sincero, ele só chegou e disse mãe é assim e assim só, eu sinto te dizer uma coisa dessa mas é a verdade tu vai te que encarar essa realidade e dai tive que encara mesmo. (MÃE 5-deficiência mental, 13 anos).

\section{A forma de comunicar o diagnóstico: implicações}

As implicações da forma negativa como é fornecido o diagnóstico aos pais se dão em diversos níveis, passando não somente pelas palavras que são ditas, mas também pela conduta do profissional. Dependendo da forma como esse contexto é desenvolvido, leva os pais a criarem uma série de fantasias e uma imagem distorcida do filho:

Foi na hora, não tinha terminado a cesárea ainda dai a pediatra foi lá e eu vi que quando ela nasceu foi aquele tumulto lá olhar e voltaram assim com umas caras disfarçadas. Dai eu perguntei né e disseram 'ah mãe eu não vi' a pediatra já vem falar contigo e tal, dai vem a pediatra assim em cima de mim com umas luvas e disse assim "Mãe ela nasceu com uma má formação e ela não vai andar”. Ai eu imaginei a guria toda deformada assim né, me deu aquele ... eu disse "ué". (MÃE 1 - meningomielocele - 15 dias).

Neste momento, nota-se a importância tanto da informação e esclarecimentos, como da visualização, pois se isso não ocorrer e o período antes de os pais verem o bebê for grande, mais distorcido e fixado pode passar a ser o conceito sobre a condição dele (Klaus e cols., 2000). Pode-se constatar, entre os entrevistados, que a forma negativa de expor o diagnóstico, serviu de estimulo para buscarem recursos para que o filho melhore e a vida dele chegue mais perto do esperado. Assim, a notícia não é seguida de informações, orientações e esclarecimentos para minimizar o choque e os pais sentirem-se encorajados a buscar recursos. Pelo contrário, o que os move é o intenso sofrimento e a tentativa de amenizar sua sensação de impotência perante o problema do filho:

Eu até acho que se eu tivesse ficado assim, não fosse atrás, não fosse procurar outros recursos eu acho que eu tinha me estacionado naquilo que ela falou ali e tinha ficado [...], mas é que eu não parei né, quando ela me disse que era aquilo ali, eu disse bom se é isso, se ela tem esse problema eu vou procurar um recurso que eu possa pelo menos dar uma vida normal pra ela... (M $\tilde{A} E 2$ - hemiparesia, um ano $e$ seis meses).

... eu disse: "não, vô em frente, vô levar ele pra melhorar devagarinho, que eu já conhecia uma criança excepcional, eu já tinha conhecimento que tinha que fazer tratamento, então, determinou em não deixar ele parar". [...] E foi isso, né, me determinou pra não deixar ele sempre vegetando, ou, passasse os anos e nada de melhora. (MÃE 8, má-formação congênita do corpo caloso, 12 anos).

Assim, o reconhecimento de que a criança, apesar de suas limitações é o filho que foi gerado e, portanto, precisa ser cuidado e amado, em muitos casos fala mais alto, independente da forma como foi fornecido o diagnóstico:

Foi a mesma coisa porque não tem como tu muda, é o teu filho, tu tá criando, tu tem que assumi, com poblema ou sem poblema tu tem que assumi, eu acho que na vida real tem que se assim (MÃE 5 deficiência Mental, 13 anos).

É teu filho, né [...] tu não vai jogar na lata do lixo, ai a gente procurou sempre dá carinho e cuidar. Cuidar o máximo que a gente possa pra ele viver melhor... As vezes tu tem uma revolta ou uma tristeza, mas tu não abandona... (MÃE 8, má-formação congênita do corpo caloso, 12 anos).

Neste sentido, na fala dos pais entrevistados que manifestaram insatisfação com a maneira com que foram informados, percebe-se que as implicações de uma forma negativa de receber o diagnóstico refletem-se no aumento de conflitos pessoais e familiares e 
na intensificação do sofrimento que naturalmente ocorre no processo de adaptação do que pela rejeição consciente da criança:

\begin{abstract}
Só no começo, quando a médica falou, claro, né, foi uma reação péssima... a reação mais do pai, o pai ficou muito... e aí o pai me culpou por isso né, [...] A forma que a médica falou foi muito assim, ela arrasou a gente, né (MÃE 7, sindrome de Down ,sete anos).

Ah eu acho que os primeiros momentos tu fica, tu olha assim, principalmente quando a criança dorme, tu fica olhando assim e diz, ai eu não acredito que a minha filha tem isso, eu não acredito que eu vou passar por isso, [...] quando tu te vê num problema assim, parece que não tem nada que tu fale que vai conseguir te levantar sabe, nada que tu escute de outra pessoa vai conseguir te levantar, tu se sente meio impotente, porque é uma coisa que não depende de ti, ai tu se sente impotente porque tu não pode fazer nada ... (MÃE 2 - hemiparesia, um ano e seis meses).
\end{abstract}

Por outro lado, pode-se perceber na fala dos pais que consideraram boa a forma como o profissional informou o diagnóstico, que esta contribuiu não somente para evitar conflitos pessoais e familiares maiores, mas influencia a forma com que os pais se relacionam com a criança:

Eu acho que o jeito que eles disseram tava bom, né, porque, eu tava desesperada, e se eles tivessem me contado, todos os problema que ela tivesse, assim, na hora, não sei o que seria de mim hoje, que eu não aguentava. E o jeito que eles foram contando aos pouquinhos, eu acho que foi bem melhor. (MÃE 3, atraso neuropsicomotor, sopro cardíaco, três anos).

... mudou porque a gente não sabia como lidar com ele também né, porque antes a gente lidava num jeito dai depois mudou todo o esquema, porque a gente às vezes tava fazendo errado, não tava correto, e ai ele não entendia direito o que eu, a gente falava... (MÃE 5 - deficiência mental, 13 anos).

\section{A palavra dos pais}

Para os pais, receber a notícia de que o seu filho possui deficiência é por si só um momento muito difícil e doloroso. No entanto, referem que a forma e o momento em que o profissional vai abordá-los para informar o diagnóstico é de extrema importância para aumentar ou diminuir o sofrimento e aceitar melhor a realidade. Segundo estudo realizado por Nursey, Rohde e Farmer (1991), os pais pensam que devem ser protegidos de um choque ainda maior em relação ao diagnóstico do filho. Além disso, pensam que devem ser informados o quanto antes sobre os problemas da criança, ao contrário do que disseram os profissionais entrevistados no mesmo estudo. Baseados em suas experiências os pais entrevistados neste estudo apontam qual a melhor maneira de serem informados, que lhes ajudariam a encarar a realidade com menos sofrimento:

\begin{abstract}
Na minha opinião eles deviam de falar, esclarecer, oh, o seu filho é assim, vai ter tal problema, como que vocês vão ter que agir, explicar aos pais pra eles terem uma noção de como é que deveria de lidar com a criança também né [...] eu acho isso muito importante, que tem muitas pessoa que abandonam o filho em casa [...], isso ai pra mim foi muito importante, se eu não tivesse talvez conhecido essa parte do setor que tinha pra criança especiais, a gente hoje não, eu não taria aqui hoje, eu taria entocada dentro de casa sem saí como tem certos pais que eu conheço que isso na vida real acontece porque a gente vê os pobrezinho lá num canto atirado... (MÃE 5-deficiência mental, 13 anos).
\end{abstract}

Além disso, os pais deixam claro que precisam ser apenas informados, esclarecidos e orientados, assim como compreendidos em seu sofrimento e reações, contando com a empatia dos profissionais, nos quais depositam esperança de uma vida melhor para o filho. Assim, a maneira de colocar o diagnóstico se mostra uma contribuição de extrema importância:

Tu pode conseguir ter um controle, tu pode conseguir ter um controle emocional, pensar e tu ser forte naquele momento, tu aceita e dizer não 'tá esse problema é isso, agora vamos pensar isso tem chance, tem chance', então segurar nessa chance e ir em

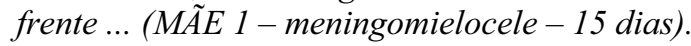

\section{CONSIDERAÇÕES FINAIS}

A partir deste estudo sobre as implicações da maneira como é fornecido o diagnóstico no processo de aceitação ou rejeição da criança com deficiência, é possível levantar algumas questões significativas. Ao longo do trabalho, pode-se perceber que este tema surge como um aspecto negligenciado na vivência dos pais ao receberem o diagnóstico de sua criança com deficiência. Dos oito pais entrevistados, apenas três consideraram boa a forma como foram informados e orientados a respeito dos problemas do filho, sendo que três consideraram péssima e dois consideraram ruim. 
Além disso, percebe-se no relato dos pais uma carga intensa de sofrimento ao lembrar do modo como foram informados. Cabe destacar que, a notícia a ser dada, inevitavelmente frustrará os pais e trará à tona uma série de mecanismos de reação que podem passar pela raiva ao portador de más notícias, independente de como são informados. No entanto, é possível perceber que há formas mais adequadas de informar os pais, evitando a intensificação do sofrimento neste momento naturalmente difícil. No entanto, um estudo realizado por Höher e Wagner (2006), entrevistou médicos e enfermeiros quanto à vivência e ao preparo para informar e orientar pais de crianças com deficiências e os profissionais julgaram que não se encontram tecnicamente preparados para informar o diagnóstico e orientar esse grupo de pais. Além disso, segundo Pasqualin (2001), os profissionais de saúde que atendem esse público demonstram ansiedade ao lidar com crianças deficientes, muitas vezes inviabilizando o diálogo com os pais, fator essencial para promover o desenvolvimento das potencialidades destas crianças.

No entanto, de acordo com os pais entrevistados as implicações da forma inadequada com que receberam a notícia, surgem de um ponto de vista em que o amor e sentimento materno/paterno são preponderantes, o que impede que sentimentos iniciais de rejeição sejam mantidos. Embora tais relatos possam refletir o que é socialmente, não inconscientemente desejado, o relato dos pais aponta que as implicações se refletem, mais explicitamente, na intensificação das reações de choque, frustração e negação e consequentemente num maior sofrimento provocado pela maneira como é fornecida a notícia, o que em grande parte pode ser evitado. Por outro lado é possível perceber que quando a informação é fornecida da maneira adequada e é considerada boa pelos pais, estes referem uma mudança de atitude frente ao filho de modo que possam corresponder com as suas reais necessidades, sem subjugá-las ou criar falsas expectativas. Por esse motivo pode-se perceber que os sentimentos negativos expressos pelos pais entrevistados, quando recebem o diagnóstico, estão mais fortemente relacionados à inadequação de como é dada a notícia, do que com o próprio impacto que ela normalmente causa. Isso reforça a importância do momento do diagnóstico e sua influência no resultante clima emocional que permita a aceitação da criança com deficiência no aparato psíquico dos pais e consequentemente no da família e da sociedade.

Diante disso, percebe-se a necessidade e importância, já apontada por alguns autores (Bazon, Campanelli
\& Blascovi-Assis, 2004; Caprara \& Rodrigues, 2004; Davies, Davis \& Sibert, 2003), de medidas de humanização dos cursos de saúde e de profissionais, tanto no sistema privado quanto no público, uma vez que o vínculo entre profissional e paciente, no momento do diagnóstico, influenciará atitudes familiares posteriores em relação ao indivíduo com deficiência.

Finalizando, cabe ressaltar que este trabalho e as questões levantadas não pretendem ser conclusivas nem generalizadas. Reconhecendo as suas limitações, este busca ser uma forma de alertar para a importância do momento do diagnóstico e suas influências para as atitudes e percepções dos familiares ao longo da vida do indivíduo com deficiência. Uma questão que, em muitas instituições de saúde, é ainda pouco ou nada valorizada.

\section{REFERÊNCIAS}

Amorim, S. T. S. P., Moreira, H., \& Carraro, T. E. (1999). Amamentação em crianças com síndrome de Down: A percepção das mães sobre a atuação dos profissionais de saúde. Revista de Nutrição, 12(1), 91-101.

Bardin, L. (1977). Análise de conteúdo (L. A. Reto \& A. Pinheiro, Trads.). Lisboa: Edições 70.

Bazon, F. V. M., Campanelli, E. A., \& Blascovi-Assis, S. M. (2004). A importância da humanização profissional no diagnóstico das deficiências. Psicologia: Teoria e Prática, 6(2), 89-99.

Brunhara, F., \& Petean, E. B. L. (1999). Mães e filhos especiais: Reações, sentimentos e explicações à deficiência da criança. Paidéia, 9(16), 31-40.

Buscáglia, L. (1997). Os deficientes e seus pais: Um desafio ao aconselhamento ( $3^{\mathrm{a}}$ ed). Rio de Janeiro: Record.

Canho, P. G. M., Neme, C. M. B., \& Yamada, M. O. A. (2006). A vivência do pai no processo de reabilitação da criança com deficiência auditiva. Estudos de Psicologia, 3(3), 261-269.

Caprara, A., \& Rodrigues, J. (2004). A relação assimétrica médico-paciente: Repensando o vínculo terapêutico. Ciência e Saúde Coletiva, 9(1), 139-146.

Castro, E. K., \& Piccinini, C. A.(2002). Implicações da doença orgânica crônica na infância para as relações familiares: Algumas questões teóricas. Psicologia: Reflexão e Crítica, 15(3), 625-635.

Cohen, M. D., Ardore, M., Honda, R. A., Samejina, A., Sarruf, M. C., \& Silva, B. P. A. (1994). Ações integradas na reabilitação de crianças portadoras da síndrome de Down. Em A. M. Kudo, E. Marcondes, M. L. F. Lins, L. T. Moriyama, M. L. L. G. Guimaraes, R. C. T. P. Juliani \& S. A. Pierri (Orgs.), Fisioterapia, fonoaudiologia e terapia ocupacional em pediatria (pp. 266-281). São Paulo: Sarvier.

Davies, R., Davis, B., \& Sibert, J. (2003). Parents' stories of sensitive and insensitive care by paediatricians in the time leading up to and including diagnostic disclosure of a life-limiting condition in their child. Child: Care, Health and Development, 29, 77-83 
Ferraretto, I., Ferreira, A., Ignacio, A., Prado, A. E., Pinto, M. C. F., Moura, M. J., \& Rizzo, A. M. P. P. (1994). Ações integradas na reabilitação de crianças portadoras de paralisia cerebral. Em A. M. Kudo, E. Marcondes, M. L. F. Lins, L. T. Moriyama, M. L. L. G. Guimaraes, R. C. T. P. Juliani \& S. A. Pierri (Orgs.), Fisioterapia, fonoaudiologia e terapia ocupacional em pediatria (p. 282-290). São Paulo: Sarvier.

Fiamenghi Jr., G. A., \& Messa, A. A. (2007). Pais, filhos e deficiência: Estudos sobre as relações familiares. Psicologia: Ciência e Profissão, 27(2), 236-245.

Goes, F. A. B. (2006). Um encontro inesperado: Os pais e seu filho com deficiência mental. Psicologia: Ciência e Profissão, 26(3), 450-461.

Goldenstein, E. (1998). Sua majestade o bebê: Conversando com papai e mamãe. São Paulo: Casa do Psicólogo.

Graungaard, A. H., \& Skov, L. (2007). Why do we need a diagnosis? A qualitative study of parents' experiences, coping and needs, when the newborn child is severely disabled. Child Care, Health and Development, 33(3), 296-307.

Höher, S. P., \& Wagner, A. D. L. (2006). A transmissão do diagnóstico e de orientações a pais de crianças com necessidades especiais: A questão da formação profissional. Estudos de Psicologia, 23(2), 113-125.

Klaus, K., Kennel, J., \& Klaus, P. (2000). Vinculo. Porto Alegre: Artmed.

Lago, C. P. (2001). Manifestações psicológicas em mães de crianças portadoras de fissuras lábio-palatal. Dissertação de mestrado não-publicada. Pontifícia Universidade Católica do Rio Grande do Sul, Porto Alegre.

Maldonado, M. T., Dickstein, J., \& Nahoum, J. C. (2002). Nós estamos grávidos $\left(12^{\mathrm{a}} \mathrm{ed}\right)$. São Paulo: Saraiva.

Mendes, E. G., Nunes, L. R. O., \& Ferreira, J. R. (2002). Diagnóstico e caracterização de indivíduos com necessidades educacionais especiais: Produção científica nacional entre 1981 e 1998. Temas em Psicologia da SBP, 1, 11-25.

Molina, S. E. (1998). O bebê da estimulação precoce. Em Centro Lydia Coriat (Org.), Escritos da criança: Vol. 5 (pp. 11-14). Porto Alegre: Centro Lydia Coriat.

Moreno, G. (1996). Síndrome de Down, um problema maravilhoso. Brasília: Corde.

Núñez, B. (2003). La familia con un hijo con discapacidad: Sus conflictos vinculares. Archivos Argentinos de Pediatría, 101(2), 133-142.
Nursey, A. D., Rohde, J. R., \& Farmer, R. D. T. (1991). Ways of telling new parents about their child and his or her mental handicap: A comparison of doctors' and parents' views. Journal of Mental Deficiency Research, 35, 48-57.

Oliveira, V. Z., Oliveira, M. Z., Gomes, W. B., \& Gasperin, C. (2004). Comunicação do diagnóstico: Implicações no tratamento de adolescentes doentes crônicos. Psicologia em Estudo, 9(1), 9-17.

Parazzi, M. M., \& Dupas, G. (2005). Compreendendo o significado de ser mãe de uma criança em problema de desenvolvimento. Revista Paulista de Enfermagem, 24(1), 40-46.

Pasqualin, L. (2001). Relação profissional de saúde e família de crianças com deficiência: Ansiedade que inviabiliza o diálogo. Boletim de Psicologia, 51(115), 215-234.

Quine, L., \& Rutter, D. R. (1994). First diagnosis of severe mental and physical disability: A study of doctor-parent communication. Journal of Child Psychology and Psychiatry, 35, 12731287.

Rossel, K. C. (2004). Apego y vinculación en el síndrome de Down: Una emergencia afectiva. Revista Pediatría Electrónica, 1(1), 1-8.

Silva, N. L. P., \& Dessen, M. A. (2001). Deficiência mental e família: Implicações para o desenvolvimento da criança. Psicologia: Teoria e Pesquisa, 17(2), 133-141.

Silva, S. F. (1988). Experiências e necessidades de mães após o diagnóstico de deficiência mental do filho. Dissertação de mestrado não-publicada, Universidade Federal de São Carlos.

Soar Filho, E. J. (1998). A interação médico-cliente. Revista da Associação Médica Brasileira, 44(1) 35-42.

Starke, M., \& Moller, A. (2002). Parents' needs for knowledge concerning the medical diagnosis of their children. Journal of Child Health Care, 6, 245-257.

Telford, C. W., \& Sawrey, J. M. (1988). O individuo excepcional ( $5^{\mathrm{a}}$ ed.). Rio de Janeiro: Livros Técnicos e Científicos.

Viana, M. L., Giacomoni, C. H., \& Rashid, L. "O que fiz por merecer?" Aspectos psicológicos da relação mãe-filho malformado. Psico, 25(1), 91-99.

\section{Sobre as autoras:}

Recebido: 08/01/2008 Última revisão: 07/12/2008 Aceite final: 08/12/2008

Síglia Pimentel Hoher Camargo: Psicóloga (UFSM) e Mestre em Psicologia do Desenvolvimento pela Universidade Federal do Rio Grande do Sul (UFRGS).

Angélica Dotto Londero Wagner: Psicóloga (PUC-RS), Mestre em Psicologia pela Pontifícia Universidade Católica do Rio Grande do Sul (PUC-RS) e Professora Assistente do Departamento de Psicologia da Universidade Federal de Santa Maria (UFSM).

Endereço para correspondência: Universidade Federal de Santa Maria - Rua Marechal Floriano Peixoto, 1750, $3^{\circ}$ andar, Sala $309-$ 97015-372 Santa Maria - RS. Endereço eletrônico: sigliahoher@yahoo.com.br. 